\title{
Research Paper: Frequency of Patient Complaints Before and After Legal Medicine Consultation in Orthopedic Ward
}

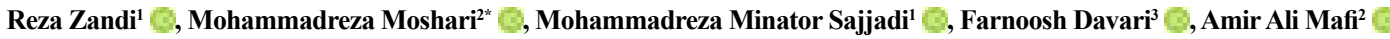

1. Department of Orthopedic Surgery, Faculty of Medicine, Taleghani Hospital, Shahid Beheshti University of Medical Sciences, Tehran, Iran.

2. Department of Anesthesiology, Faculty of Medicine, Taleghani Hospital, Shahid Beheshti University of Medical Sciences, Tehran, Iran.

3. Legal Medicine, Taleghani Hospital, Shahid Beheshti University of Medical Sciences, Tehran, Iran.

\begin{tabular}{|c|c|}
\hline $\begin{array}{l}\text { Use your device to scan } \\
\text { and read the article online }\end{array}$ & $\begin{array}{l}\text { ditation: Zandi R, Moshari MR, Minator Sajjadi MR, Davari F. Frequency of Patient Complaints Before and After Le- } \\
\text { gal Medicine Consultation in Orthopedic Ward. International Journal of Medical Toxicology and Forensic Medicine. 2021; } \\
\text { 11(1):32525. https://doi.org/10.32598/ijmtfm.v11i.32525 }\end{array}$ \\
\hline a & d of https://doi.org/10.32598/ijmtfm.v11i.32525 \\
\hline
\end{tabular}

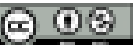

Article info:

Received: 11 Oct 2020

First Revision: 18 Oct 2020

Accepted: 10 Nov 2020

Published: 13 Apr 2021

\section{Keywords:}

Legal medicine, Orthopedics, Taleghani Hospital

\section{ABSTRACT}

Background: Patient who complain of the health community are unpleasant and may endanger the honor of the medical community. However, patients' complaints can improve the quality of medical services, increase the accuracy of the medical staff, and reduce diagnostic and treatment costs. The aim of this study was to investigate the prevalence of patients' complaints before and after legal medicine consultation in the orthopedic ward of Taleghani hospital in Tehran, Iran.

Methods: This retrospective cross-sectional study investigated the frequency of the complaints of 460 patients before and after legal medicine consultation from spring 2011 to winter 2017. Data were analyzed by excel.

Results: The results of this study showed that the frequency of complaints was lowest in spring and highest in fall. The number of complaints and frequencies also decreased over time compared with the previous year. The lowest number of complaints was in 2011 and the highest in 2013.

Conclusion: In this study, performing legal medicine consultation in Taleghani hospital in Tehran, Iran reduced the number of registered complaints.

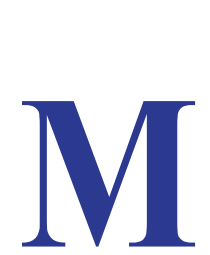

\section{Introduction}

edical complaints are the dissatisfaction of the patient and their family and relatives, which need a response [13]. Due to the availability of modern information systems and the increasing level of education and public education, patients and their families participate in healthcare and treatment of their diseases. Moreover, complaints about the quality of health care have increased dramatically $[4,5]$. Consequently, minor complaints are considered essential to the quality of care to improve the standards of care [6-8].

Handling complaints is also very useful. Patients' complaints are an important and valuable source of improve-

*Corresponding Author:

Mohammadreza Moshari, MD.

Address: Department of Anesthesiology, Taleghani Hospital, Shahid Beheshti University of Medical Sciences, Tehran, Iran.

Tel: +98 (21) 22432595

E-mail: rmoshari@sbmu.ac.ir 
ment in performance and quality of hospital care [9] because patients are more sensitive to interventions [10, 11]. In most hospitals, the most common cause of the complaint is interpersonal problems. According to some studies, more than one-third of all complaints are related to communication difficulties, and in some studies, services are the main cause of patients' complaints [12-15]. International reports on the abundance of complaints of medical practitioners in various countries show that there has been an increase in complaints despite significant scientific advances and new technology in the medical field [16].

Relevant studies show an increased incidence of complaints about the quality of health care provided to patients. Complaints can also push the quality of care through legal medicine $[17,18]$. On the other hand, the complaint can provide performance feedback on physicians' work, identify weaknesses and poor performance, and provide opportunities to design strategies to improve the quality of care [19]. Complaints can also indicate in which sections of the hospital, the process of providing services to their clients is problematic; thus, hospital managers and staff can analyze and resolve these problems with further investigations [20].

Generally, reviewing the rate and causes of complaints from medical staff and their resolution is a step towards increasing patient satisfaction and increasing hospital efficiency. Also, limited studies are available on patients' complaints in Iran, thus, recording and handling complaints have been considered as one of the important domains of clinical service governance in hospitals affiliated to medical universities. Therefore, the aim of this study was to investigate the prevalence of patients' complaints before and after legal medicine consultation in the orthopedic ward of Taleghani Hospital in Tehran, Iran.

\section{Materials and Methods}

The present study was a retrospective descriptive crosssectional study performed on patients undergoing orthopedic surgery in the orthopedic ward of Taleghani hospital, Tehran, Iran from March 2011 to December 2017. In this study, all the complaints registered in Taleghani Hospital in Tehran were studied before and after medical consultation to resolve their problems as soon as possible. The experts of the Department of Inspection and Supervision from the Treatment Affairs of Shahid Beheshti University of Medical Sciences developed the data collection tool. In this study, the demographic questionnaire and a questionnaire regarding the registration and type of complaints were completed from patients. All com- plaints (written, oral, and via telephone) registered at the Taleghani Hospital complaints office were reviewed.

Data were analyzed by Excel software using descriptive statistics, tables, and graphs. The research council and ethics committee of Shahid Beheshti University of Medical Sciences approved this study (IR.SBMU.RETECH.REC.1399.297).

\section{Results}

The total number of complaints before legal medicine consultation filed by the Medical Council and the Legal Medicine Organization of Tehran was 810 (567 males and 243 females), was reduced to 460 were after consultation from March 2011 to December 2017. The mean age of these patients was 44 years old. All complaints filed after legal medicine consultation from spring 2011 to winter 2017 are listed in Figure 1 and Table 1. As can be seen in the table and diagram, in 2011, the highest frequency and number of complaints were recorded in fall and the lowest in spring. In 2012, the highest rate was recorded in summer and the lowest in spring, in 2013, the highest in fall and the lowest in spring, in 2014, the highest in summer and lowest in winter, in 2015, the highest in fall and lowest in spring and winter, in 2016 highest in fall and lowest in winter, and in 2017, the highest rate was recorded in summer and lowest was recorded in spring.

\section{Discussion}

According to the results of this study, the number of complaints has been increasing in recent years. It can be justified that increasing the burden on clients on one hand, and the lack of promotion of human resources, on the other hand, is one of the factors contributing to the increase in dissatisfaction with clients. Reducing the causes of dissatisfaction and correcting them can reduce the burden of clients' dissatisfaction [21-24]. Also, dissatisfaction can be greatly reduced by informing the clients about the course of the treatment process [25].

Trzeciak et al. emphasized the same factors and insufficient capacity to treat patients as factors causing dissatisfaction [26]. In the study of Isfahani et al., patients admitted to surgical, neurosurgical, and internal medicine wards had a longer stay in the emergency department due to the length of counseling times and the reluctance of patients to undergo treatment by another service, and consequently, they were more dissatisfied [27]. 


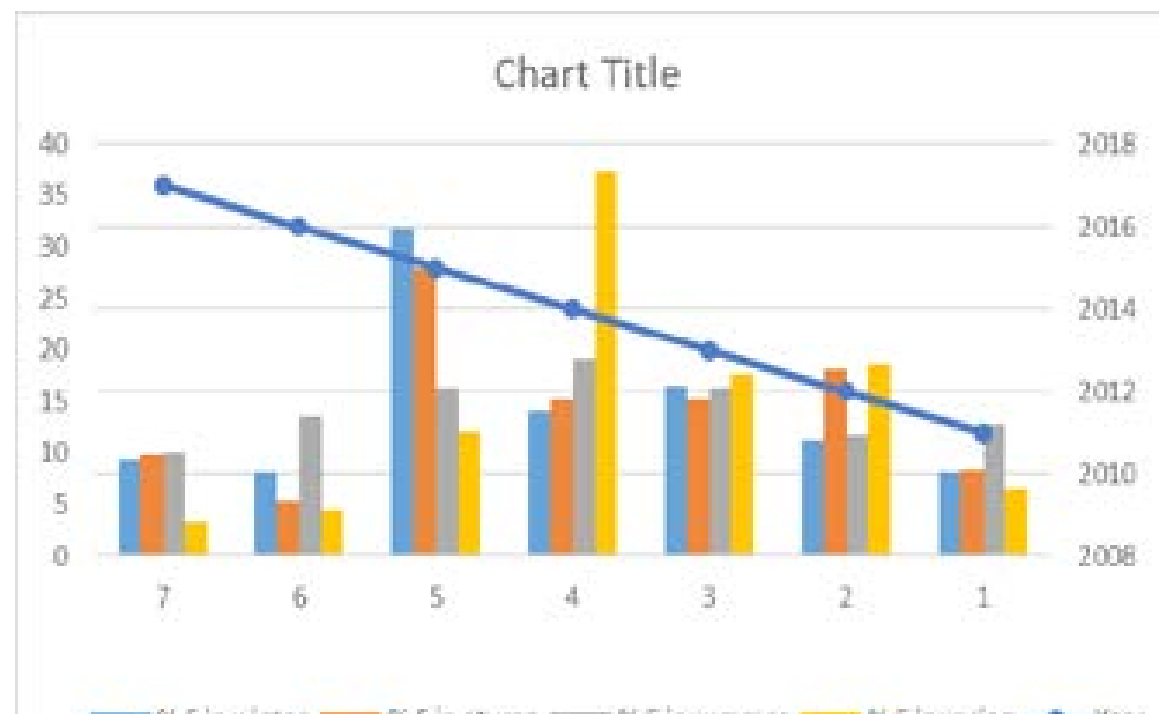

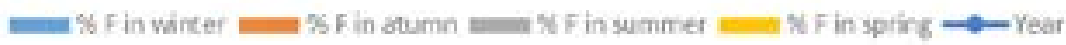

International Journal of

Medical Toxicology \& Forensic Medicin

Figure 1. The frequency (\%) of patients' complaints in the orthopedic ward of Taleghani hospital in Tehran from 2011 to 2017

In the study by Soleimanpour et al., the highest satisfaction was observed in the relationship between the patient and the physician, security officers, and nurses [28].

Zarei et al. assessed the impact of service quality on patient satisfaction in private hospitals in Iran and a strong and direct relationship was found between service quality and patient satisfaction. However, no significant relationship was found between the quality of the physical environment and patient satisfaction. These results are in line with the results of this study indicating that the quality of service delivery in interpersonal relationships is a major cause of dissatisfaction [29].

Amoee et al. also reported that in surgical specialties, difficulties in surgical techniques, and surgeons' lack of knowledge regarding new surgical procedures, and in the internal medicine and pediatric fields, no adequate justification of patients before treatment and the lack of communication between the physician and patient have

Table 1. The frequency and percentage of patients' complaints in the orthopedic ward of Taleghani Hospital in Tehran from 2011 to 2017

\begin{tabular}{cccccccccc}
\hline Year & A & B & C & D & E & F & G & H & I \\
\hline 2011 & 3 & 3.29 & 11 & 10 & 13 & 9.84 & 9 & 9.27 & 36 \\
2012 & 4 & 4.39 & 15 & 13.63 & 7 & 5.3 & 8 & 8.24 & 64 \\
\hline 2013 & 11 & 12.08 & 18 & 16.36 & 37 & 28.03 & 31 & 31.95 & 97 \\
\hline 2014 & 34 & 37.36 & 21 & 19.09 & 20 & 15.15 & 14 & 14.13 & 89 \\
\hline 2015 & 16 & 17.58 & 18 & 16.36 & 20 & 15.15 & 16 & 16.49 & 70 \\
\hline 2016 & 17 & 18.68 & 13 & 11.81 & 24 & 18.18 & 11 & 11.34 & 65 \\
\hline 2017 & 6 & 6.59 & 14 & 12.72 & 11 & 8.33 & 8 & 8.24 & 39 \\
\hline Total & 91 & 100 & 110 & 100 & 132 & 100 & 97 & 100 & 460 \\
\hline
\end{tabular}

A. Number of complaints in spring; B. Percentage of complaints in spring; C. Number of complaints in summer; D. Percentage of complaints in summer; E. Number of complaints in fall; F. Percentage of complaints in fall; G. Number of complaints in winter; H. Percentage of complaints in winter; I. Total complaints 
been the cause of complaints [30]. Ellis et al. showed that paying attention to patients during treatment can increase satisfaction and decrease patient complaints [31].

Jafari et al. reported that patients' complaints of hospitals and physicians have increased in recent years [32], which is in line with the present study. However, in the present study, after legal medicine consultation, patients' complaints declined.

Khomarnia et al. reported that the number of complaints registered in Shiraz public hospitals increased over a five-year period [33].

Similar results were obtained in the studies of Mirzaaghaeei, et al. and Siabani et al. [1, 34]. Also, Mirzaaghaeei, et al. showed that $62 \%$ of the total complaints of hospitals are related to physicians [1]. In the Anderson et al. study, the results showed that 1308 complaints were recorded in one of Australia's largest hospitals over a 30-month period [35].

Ebrahimipoor et al. reported that the lack of satisfaction with health care services, inappropriate treatment, and lack of attention to welfare facilities are the most important causes of complaints in a hospital in Mashhad [36]. Rojas considered behavioral variables as the most important causes of patients' complaints about the health system [37]. Badakhshi et al. and Barriere et al. emphasized that the attention of health care providers to patients' rights is mandatory and also the observance of professional and ethical standards in health care providers plays an important role in reducing patient complaints $[19,38]$.

In the study by Sadeghi et al., it was observed that the number of complaints registered in public hospitals of Iran increased after the implementation of the health system evolution plan because it resulted in systematic registration and special attention to the complaints in the hospitals. Most of the complaints have also been recorded in the emergency department of hospitals [20].

Consistent with the present study, Ndetan et al. conducted a national survey of patients' complaints about the health system in the UK and 30\% of respondents reported receiving advice/consulting from their provider, and $88 \%$ reported that the advice given to them caused a decrease in the rate of their complaints. Therefore, by providing appropriate information and advice, patients' complaints can be largely avoided [39].
Murff et al. showed that $19 \%$ of patients complained of problems after surgery [40]. Daniel et al. reported that $64 \%$ of patients complained of clinical care, $22 \%$ of poor physician-patient and nurse-patient communication, and inappropriate and immoral behaviors by physicians and nurses [41]. In general, patients' complaints about medical staff and hospitals can have various effects that have always been addressed in various studies, some of which were discussed in this article.

Athar et al. believed some factors can decrease the number of complaints, such as appropriate doctor-patient relationship, a full explanation of the treatment process, choosing patients appropriately, no exaggeration of treatment results, avoiding methods not trained yet, skilled and experienced physicians, observing medical ethics and professional commitment, continuous study and upgrading medical knowledge, and obtaining informed consent [42]. Parsapour et al. indicated that enhancing the doctor-patient relationship is an effective factor in preventing complaints [43].

Jafarian et al. showed that behaviors based on physicians' professional commitment to patients could prevent a majority of complaints [44]. Dargahi et al. in their study showed that there is no significant relationship between the number of complaints made by patients and their companions after the implementation of the Health Transformation Plan compared with before in the studied hospitals. There was also a positive and significant relationship between the number of complaints before and after the implementation of the Health Transformation Plan and the status of patients in the hospital, with complaints regarding the issues, including doctors and nurses, patients' life status, and type of hospitalization.

In general, after the implementation of the Health Transformation Plan, there was an increase in the number of patients' complaints of doctors and nurses, the condition of patients being treated, especially in outpatient wards; thus, in order to correct weaknesses in the hospital services, in this study, communication skills training courses were developed and implemented to strengthen the physician-patient-nurse-patient relationship, and the necessary arrangements were made to repair the indicators of the treatment process in the studied hospitals [45]. Aiken et al. showed that increasing the quality of care, favorable environmental conditions and low costs in European hospitals play a role in reducing patients' complaints of nurses [46]. Yu-Hua et al. also reported an increase in the frequency of patients' complaints of nurses due to disrespect to patients [47]. 


\section{Conclusion}

Legal medicine counseling in this study at Taleghani Hospital in Tehran, Iran reduced the number of registered complaints. It should be noted that to reduce the number of complaints, in addition to treating patients, the principle of respect for the patient should always be taken into consideration by all staff. In addition, improving the quality of services in the health system, reducing waiting time, and timely assignment of patients can significantly reduce the number of complaints, which in turn will improve the quality of services and increase the satisfaction of patients and their companions. Treatment and service teams should receive regular periodic monitoring, not only to improve their performance but also to significantly reduce their dissatisfaction.

\section{Ethical Considerations}

\section{Compliance with ethical guidelines}

The Research Council and Ethics Committee of Shahid Beheshti University of Medical Sciences approved this study (IR.SBMU.RETECH.REC.1399.297).

\section{Funding}

All financial aspects of this project have been provided by Taleghani Hospital.

\section{Author's contributions}

Conceptualization: Reza Zandi and Mohammadreza Moshari; Methodology: Reza Zandi, Mohammadreza Moshari, and Mohammadreza Minator Sajjadi; Investigation: Farnoosh Davari; Writing - orginal draft: Reza Zandi and Amir Ali Mafi; Funding Acquisition: Mohammadreza Moshari; Resources: Amir Ali Mafi; Supervision: Mohammadreza Moshari.

\section{Conflict of interest}

The authors declared no conflict of interests.

\section{Acknowledgements}

We would like to thank all the staff at Taleghani Hospital who have helped us in this research project.

\section{References}

[1] Mirzaaghae F, Moeinfar Z, Eftekhari S, Rashidian A, Sedaghat M. [A study of complaints registered at three hospitals affiliated to Tehran University of Medical Sciences and factors affecting on it from march 2007 to february 2009 (Persian)]. J Hospital. 2012; 10(1):19-28. https:/ /jhosp.tums.ac.ir/article-1-66-fa.html

[2] WHO (World Health Organization). The World Health Report 2000 - Health systems: Improving performance; 2000. https://www.who.int/whr/2000/en/

[3] Rubrichi S, Battistotti A, Quaglini S. Patients' involvement in e-health services quality assessment: A system for the automatic interpretation of SMS-based patients' feedback. J Biomed Inform. 2014; 51:41-8. [DOI:10.1016/j.jbi.2014.03.003] [PMID.

[4] Griffith JR. Championship management for healthcare organizations. J Health Manag. 2000; 45(1):17-30. [DOI:10.1097/00115514-200001000-00007] [PMID]

[5] Mousavi A, Mousavi J. [Causes of patient dissatisfaction of public hospitals in Mazandaran province (Persian)]. Sci J Forensic Med. 2010; 16(2):127-33. https://www.sid.ir/fa/journal/ViewPaper.aspx?ID=136785

[6] Movahednia S, Partovishayan Z, Bastani M. [Survey of complaints and factors affecting them in Firoozgar Hospital (Persian)]. J Payavard Salamat. 2014; 8(1):25-33. http:/ / payavard. tums.ac.ir/article-1-5310-en.html

[7] Winkler F. Complaint by patients. BMJ. 1993; 306(6876):472 3. [DOI:10.1136/bmj.306.6876.472] [PMID] [PMCID]

[8] Eraker SA, Kirscht JP, Becker MH. Understanding and improving patient compliance. Ann Intern Med. 1984; 100(2):258-68. [DOI:10.7326/0003-4819-100-2-258] [PMID]

[9] Parry J , Hewage U. Investigating complaints to improve practice and develop policy. Int J Health Care Quality Assur. 2009; 22(7):663-9. [DOI:10.1108/09526860910995001] [PMID]

[10] Gillespie A, Reader TW. The healthcare complaints analysis tool: Development and reliability testing of a method for service monitoring and organizational learning. BMJ Qual Saf. 2016; 25(12):937-46. [DOI:10.1136/bmjqs-2015-004596] [PMID] [PMCID]

[11] Gharaei H, Mousavi M, Rouhbakhsh ZM, Ghaempanah A. [A study of the complaint of patients coming to the emergency ward of Khatam-ol-Anbia Eye Hospital Mashhad (Persian)]. Q Med J Mashhad Univ Med Sci. 2010; 53(1):26-32. [DOI:10.1136/bmjqs-2015-004596]

[12] Dennis B, Overton DT, Schwartz LR , Strait M. Emergency department complaint frequency: Variation by patient median household income. Ann Emerg Med. 1992; 21(6):746-8. [PMID] [DOI:10.1016/S0196-0644(05)82796-9]

[13] Taylor DM, Wolfe RS, Cameron PA. Analysis of complaints lodged by patients attending Victorian hospitals, 1997-2001. Med J Aust. 2004; 181(1):31-5. [DOI:10.5694/j.1326-5377.2004. tb06157.x] [PMID]

[14] Griffey RT , Bohan JS. Healthcare provider complaints to the emergency department: A preliminary report on a new quality improvement instrument. Qual Saf Health Care. 2006; 15(5):344-6. [DOI:10.1136/qshc.2005.015776] [PMID] [PMCID]

[15] Doig G. Responding to formal complaints about the emergency departments: Lessons from the service market- 
ing literature. Emerg Med Australas. 2004; 16(4):353-60. [DOI:10.1111/j.1742-6723.2004.00613.x] [PMID]

[16] Mc Peek B, Kitz RJ, Dripps RD, Eckenhoff JE, Vandam LD. Introduction of anesthesia: The principles of safe practice. N Engl Med J. 1973; 289:51. [DOI:10.1056/ NEJM197307052890128]

[17] Widayanti A, Subjaswadi R. Patient compliance in using antimicrobial drugs: Case study in some private pharmacies in Yogyakarta. Res Social Adm Pharm. 2012; 8(6):e18. [DOI:10.1016/j.sapharm.2012.08.043]

[18] Smith YK, Verrett RG. Evaluation of a novel device for measuring patient compliance with oral appliances in the treatment of obstructive sleep apnea. J Prosthodont. 2014; 23(1):31-8. [DOI:10.1111/jopr.12076] [PMID]

[19] Badakhshi H, Gruen A, Sehouli J, Budach V, Boehmer D. The impact of patient compliance with adjuvant radiotherapy: A comprehensive cohort study. Cancer Med. 2013; 2(5):712-7. [DOI:10.1111/jopr.12076] [PMID][PMCID]

[20] Sadeghi A, Rohani H, Davarzani S, Davarzani Z. [Trend of patients' compliance in a public hospital before and after healthcare reform implementation (Persian)]. J Hosp. 2018; 17(2):105-12. http://jhosp.tums.ac.ir/article-1-5845-en.html

[21] Boulding W, Glickman SW, Manary MP, Schulman KA, Staelin R. Relationship between patient satisfaction with inpatient care and hospital readmission within 30 days. Am J Manage Care. 2011; 17(1):41-8. [PMID]

[22] You LM, Aiken LH, Sloane DM, Liu K, He GP, Hu Y, et al. Hospital nursing, care quality, and patient satisfaction: Cross-sectional surveys of nurses and patients in hospitals in China and Europe. Int J Nurs Stud. 2013; 50(2):154-61. [DOI:10.1016/j.ijnurstu.2012.05.003] [PMID]

[23] Horwitz LI, Green J, Bradley EH. US emergency department performance on wait time and length of visit. Ann Emerg Med. 2010; 55(2):133-41. [DOI:10.1016/j.annemergmed.2009.07.023] [PMID] [PMCID]

[24] Hosseini M, Shaker H, Ghafouri H, Shokraneh F. [Chronometric study of patients' workflow and effective factors on it in emergency department of 7th Tir Martyrs Hospital of Tehran, Iran (Persian)]. J Health Admin. 2010; 13(40):13-22. http://jha.iums.ac.ir/article-1-629-en.html

[25] Yousefzadeh chabok S, Mohtasham Amiri Z, Haghdoost Z, Mohseni M, Asadi P, Kazemnezhad Leili E. [Patients discharged before and after presence of medical emergency specialists (Persian)]. J Holistic Nurse Midwifery. 2014; 24(1):6470. http://hnmj.gums.ac.ir/article-1-100-en.html

[26] Trzeciak S, Rivers EP. Emergency department overcrowding in the United States: An emerging threat to patient safety and public health. Emerg Med J. 2003; 20(5):402-5. [DOI:10.1136/emj.20.5.402] [PMID] [PMCID]

[27] Nasr-Esfahani M, Esmailian M, Nasri M. [Causes of prolonged length of stay for patients referred to the emergency department: A cross-sectional study (Persian)]. Iran J emerg Med. 2014; 1(1):45-9. [DOI:10.22037/ijem.v1i1.7312]

[28] Soleimanpour H, Gholipouri C, Salarilak S, Raoufi P, Vahidi RG, Rouhi AJ, et al. Emergency department patient satisfaction survey in Imam Reza Hospital, Tabriz, Iran. Int J Emerg Med. 2011; 4(1):2-8. [DOI:10.1186/1865-1380-4-2] [PMID] [PMCID]
[29] Zarei E, Daneshkohan A, Pouragha B, Marzban S, Arab M An empirical study of the impact of service quality on patient satisfaction in private Hospitals, Iran. Glob J Health Sci. 2015; 7(1):1-6. [DOI:10.5539/gjhs.v7n1p1]

[30] Amoee M, Soltani K, Kahani A, Najari F, Rohi M. [Survey of medical malpractice cases referred to legal medicine organization in 2000 (Persian)]. Sci J Forensic Med. 1998; 6(21):15-23. https:// www.sid.ir/fa/journal/ViewPaper.aspx?id=10870

[31] Ellis KM, Norman C, Van der Merwe A, Jeon M. Increasing patient compliance and satisfaction with physical therapy web-based applications. SAGE J. 2013; 57(1). [DOI:10.1177/1541931213571341]

[32] Jafari M, Arad H, Taghavi Z. Prevalence and causes of patient complaints of dentists in Tehran in 2003-2007 to Legal Medicine Organization of Tehran related to treatment of oral and maxillofacial surgery. Dent Res. 2008; 5(3):9-14. https:// www.sid.ir/en/Journal/ViewPaper.aspx?ID=194169

[33] Khammarnia M, Kavosi Z, Ghanbari Jahromi M, Moradi A. Impact of clinical governance on patients' compliance in Shiraz public hospitals. Payavard. 2016; 10(suppl 1):93-103. https:/ / www.sid.ir/en/journal/ViewPaper.aspx?id=509869

[34] Siabani S, Alipour AA, Siabani H, Rezaei M, Daniali S. A survey of complaints against physicians reviewed at Kermanshah Medical Council 2001-2005. J Kermanshah Univ Med Sci. 2009; 13(1):e79831. https:/ / sites.kowsarpub.com/jkums/ articles/79831.html

[35] Anderson K, Allan D, Finucane P. A 30-month study of patient complaints at a major Australian hospital. J Qual Clin Pract. 2001; 21(4):109-11. [DOI:10.1046/j.14401762.2001.00422.x] [PMID]

[36] Ebrahimipoor H, Vafaee-Najar A, Khanijahani A, Pourtaleb A, Saadati Z, Molavi Y, et al. Customers' complaints and its determinants: The case of a training educational hospital in Iran. Int J Health Plann Manag (IJHPM). 2013; 1(4):273-7. [DOI: 10.15171/IJHPM.2013.56]

[37] Rojas C, Zhou MK, Harry Khamis HJ, Lawrence P. Analysis of patterns of patient compliance after an abnormal pap smear result: The influence of demographic characteristics on patient compliance. J Low Genit Tract Dis. 2013; 17(3):298-302. [DOI:10.1097/LGT.0b013e31826b683e] [PMID]

[38] Barrière O, Li J, Nekka F. A Bayesian approach for the estimation of patient compliance based on the last sampling information. J Pharmacokinet Pharmacodyn. 2011; 38(3):333-51. [DOI:10.1007/s10928-011-9196-2] [PMID]

[39] Ndetan H, Evans Jr MW, Bae S, Felini M, Rupert R, Singh KP. The health care provider's role and patient compliance to health promotion advice from the user's perspective: Analysis of the 2006 National Health Interview Survey data. J Manipulative Physiol Ther. 2010;33(6):413-8. [DOI:10.1016/j. jmpt.2010.06.009] [PMID]

[40] Murff H, France DJ, Blackford J, Grogan EL, Yu C, Speroff $\mathrm{T}$, et al. Relationship between patient complaints and surgical complications. Qual Saf Health Care. 2006; 15(1):13-6. [DOI:10.1136/qshc.2005.013847] [PMID] [PMCID]

[41] Daniel AE, Burn RJ, Horarik S. Patients' complaints about medical practice. Med J Aust. 1999; 170(12):598-602 [DOI:10.5694/j.1326-5377.1999.tb127910.x] [PMID] 
[42] Moin A, Ostad Ali Makhmalbaf M, Davati A. Study of medical malpractice complaints in the field of dermatology and cosmetic, in the coroner's Office of Forensic Medicine, Province of Tehran, during 2002 to 2010. Dermatology and Cosmetic. 2011; 2(1):17-29. https://jdc.tums.ac.ir/browse. php?a_id $=36 \&$ sid $=1 \&$ slc_lang $=$ en

[43] Parsapour A, Bagheri A, Larijani B. [Patient rights in Iran (Persian)]. Iran J Med Ethics and Hist Med. 2010; 3(1-2):39-47. http://ijme.tums.ac.ir/article-1-247-en.html

[44] Jafarian A, Parsapour A, Hajtarkhani AH, Asghari F, Emami Razavi SA, Yalda A. A survey of the complaints entering the medical council organization of tehran in three time periods: the years ending on 20 march 1992, 20 march 1997 and 20 march 2002 Iran J Med Ethics and Hist Med. 2009; 2:67-73. [PMID] [PMCID]

[45] Hossein Dargahi, Nader Bahman, Arash Akbarzadeh. [Patients' complaints before and after implementation of health transformation plan (Persian)]. Payesh. 2018; 7(5):495-505. https://www.sid.ir/fa/journal/ViewPaper.aspx?id=349647

[46] Aiken L, Sermens W, Busse R, McKee M, Raffery AM, et al. Patient safety, satisfaction, and quality of hospital care: Cross-sectional surveys of nurses and patients in 12 countries in Europe and the United States. BMJ. 2012; 344:e1717. [DOI:10.1136/bmj.e1717] [PMID] [PMCID]

[47] Yu-Hua Lin, Hsueh-Erh LIU. The impact of workplace violence on nurses in South Taiwan. Int J Nurs Stud. 2005; 42(7):773-8. [DOI:10.1016/j.ijnurstu.2004.11.010] [PMID] 